\title{
Effect of Learning the Emotional Intelligence Parameters on Increasing the Self-Efficiency and Decreasing the Career Stress
}

\author{
Foruhar A.* MSc, Eslami M. ${ }^{1} M S c$, Sadeghi M. ${ }^{2} M S c$
}

*Counseling Department, Psychology Faculty, Allameh Tabatabaei University, Tehran, Iran 1Psychology Department, Psychology \& Educational Sciences Faculty, AlZahra University, Tehran, Iran 2Psychology Department, Psychology Faculty, Sciences \& Researches Branch, Islamic Azad University, Tehran, Iran

\begin{abstract}
Aims: Emotions and how to deal with them are part of the human personality and affect her health. Ability to evaluate and express our emotions, emotion regulation of ourselves and the others and operation of emotion is called "emotional intelligence". This study aimed to determine the effect of emotional intelligence component training on self-efficacy enhancement and reduction of occupational stress.

Materials \& Methods: The semi-experimental research was done on Tehran municipality employees in 2010. Purposeful cluster sampling was done and 30 people who had a high score of occupational stress and low occupational stress were selected and randomly assigned to experimental and control groups. Data collected by the Self-Efficacy Beliefs Questionnaire developed by Scherer and colleagues and the Occupational Stress Inventory developed by Philip L. Rice. Data were analyzed by software SPSS 16 using descriptive statistics and independent T-test and Pearson's correlation coefficient.

Findings: Self-efficacy mean score of experimental group was $64.9 \pm 6.2$ in posttest which had a significant difference with pre-test score $(51.9 \pm 8.5)$ of this group $(\mathrm{t}=5.1 ; \mathrm{p}=0.05)$. The mean score of general symptoms of stress of experimental group was $25.7 \pm 6.8$ in post-test which was significantly different from its pre-test score (32.1 \pm 5.6$)$. A negative correlation was observed between self-efficacy increase and occupational stress symptoms reduction $(\mathrm{r}=-$ $0.223 ; \mathrm{p}=0.033$ ).

Conclusion: Teaching emotional intelligence components can increase the belief of self-efficacy and reduce the syndromes of occupational stress.
\end{abstract}

Keywords

Emotional Intelligence [http://www.ncbi.nlm.nih.gov/mesh/68056348];

Burnout, Professional [http://www.ncbi.nlm.nih.gov/mesh/68002055];

Self Efficacy [http://www.ncbi.nlm.nih.gov/mesh/68020377]

*Corresponding Author

Tel: +982632305530

Fax: +982188957948

Address: $4^{\text {th }}$ Floor, No. 2, Sane'ei Dead End, $5^{\text {th }}$ Street, Dr. Fatemi Street, Tehran, Iran

aforohar1390@gmail.com

Received: October 15, 2014 


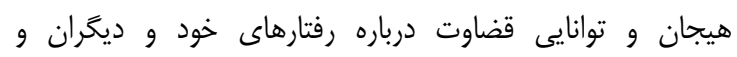

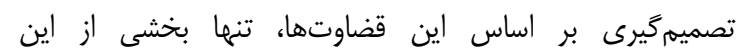

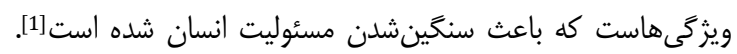

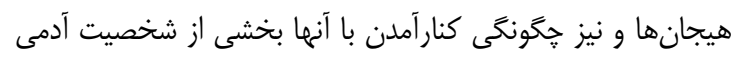

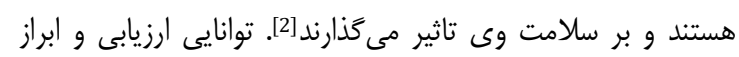

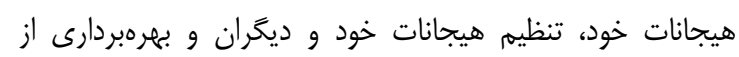

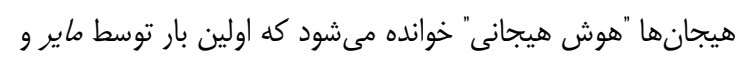
سالووى مطرح شد [3].

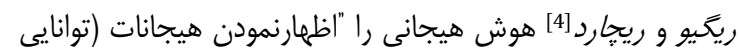

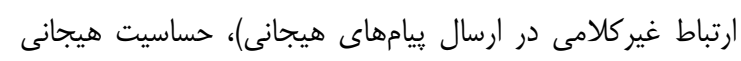

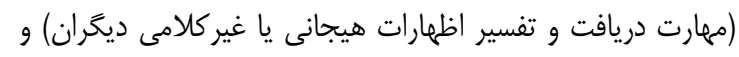

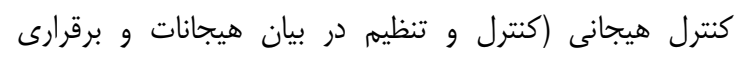

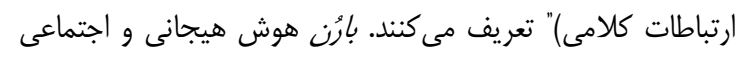

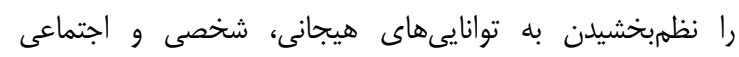

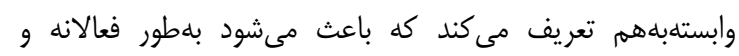

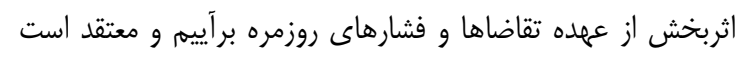

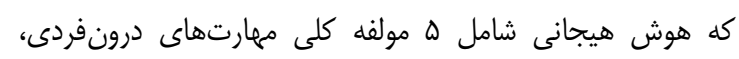

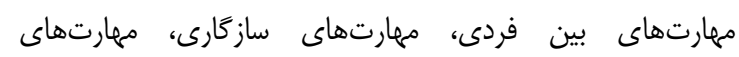

مهارتنيدگى و مهارتهاى خلق عمومى است [5.

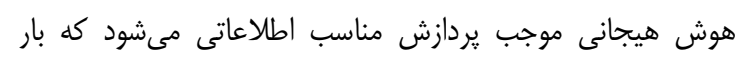

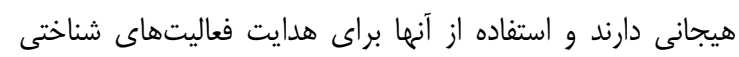

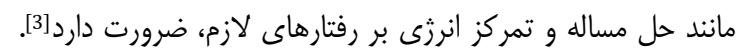

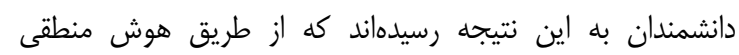

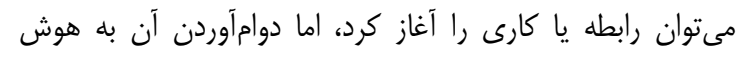

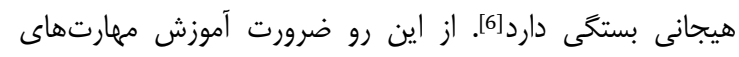

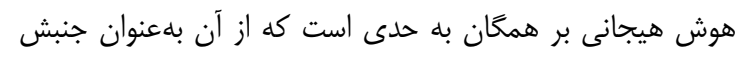

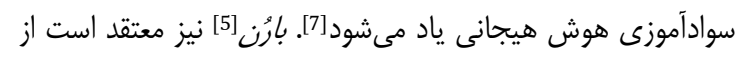

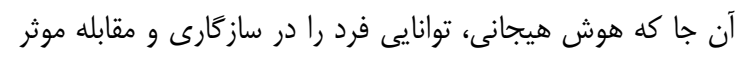

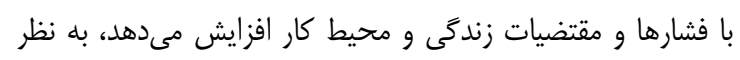

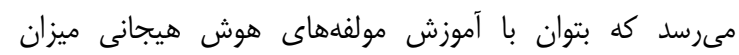

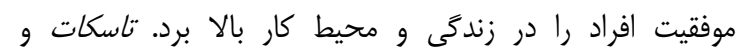

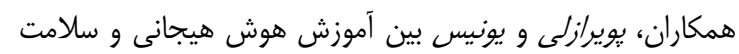

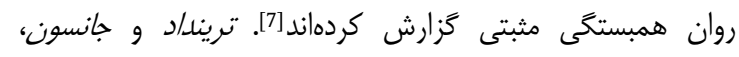

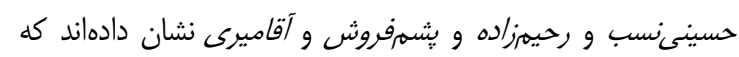

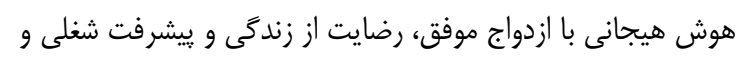

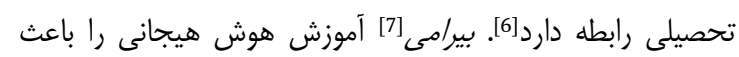

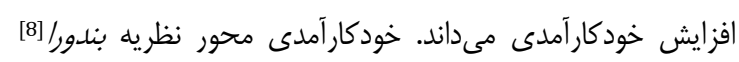

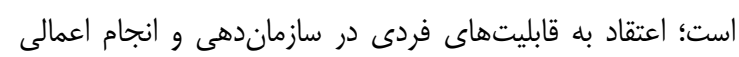

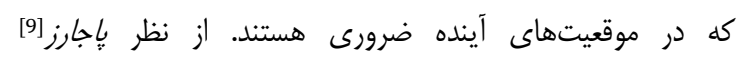

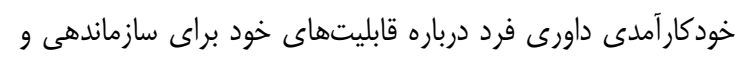

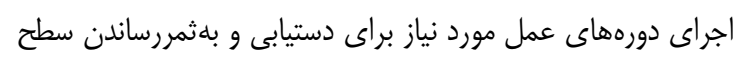

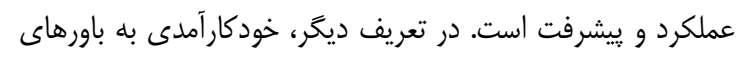

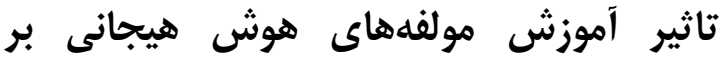

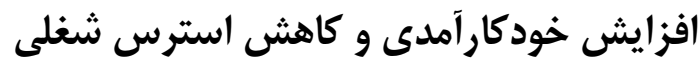

MSc

كروه مشاوره، دانشكده روانشناسى، دانشكاه علامه طباطبايى، تهران، ايران

منصوره اسلامى

كَروه روانشناسى، دانشكده روانشناسى و علوم تربيتى، دانشخاه الزهرا، تهران،

ايران

منصوره صادقى اليزان

كروه روانشناسى، دانشكده روانشناسى، واحد علوم و تحقيقات، دانشكاه آزاد

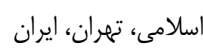

جكيده

أهداف: هيجانها و نيز هيكونكى كنارآمدن با آنها بخشى از شخصيت

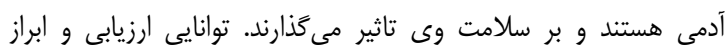

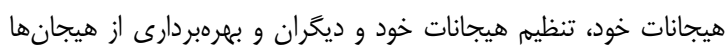

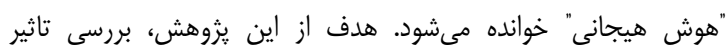

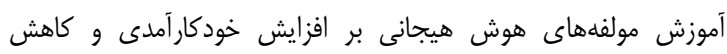
استرس شغلى بود. مواد و روشها: اين ثزوهش نيمهتجربى در جامعه آمارى كارمندان

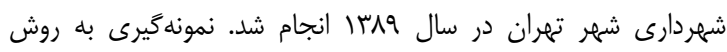

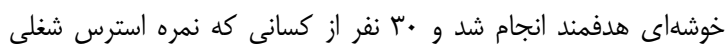

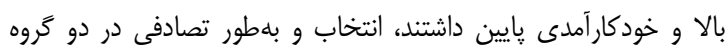

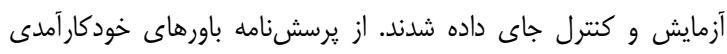

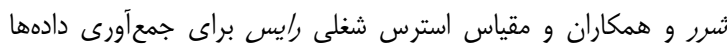

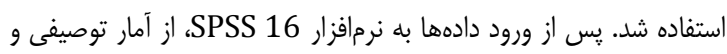

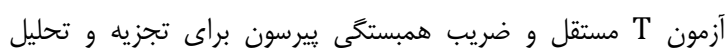

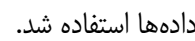

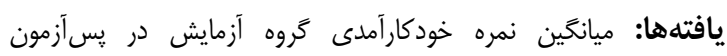

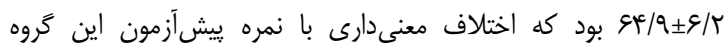

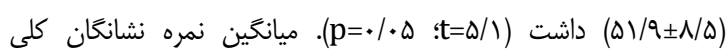
استرس در يسآزمون كروه آزمايش

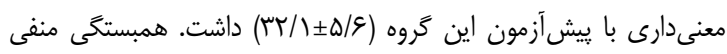

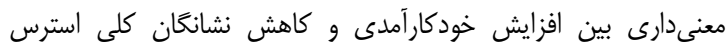

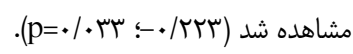

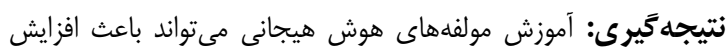

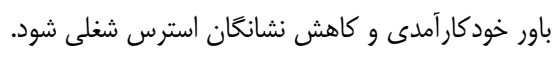

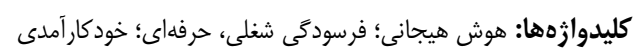

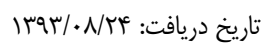

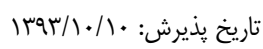

"نويسنده مسئول: تاريخ: بذرش:

مقلمها

از ميان موجوداتى كه در كره زمين زندكى مهى كنند، انسان از

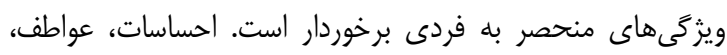

دوره •r، شماره f، زمستان rari

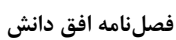




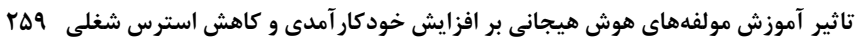

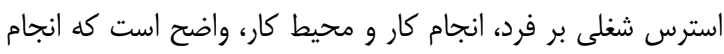

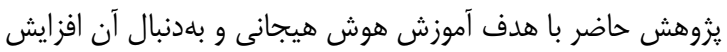

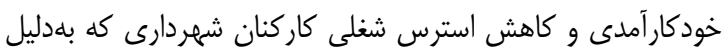

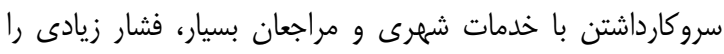

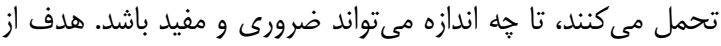

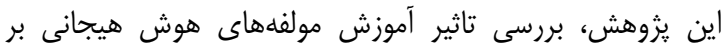
افزايش خودكارآمدى و كاهش استرس شغلى بود.

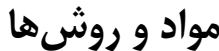

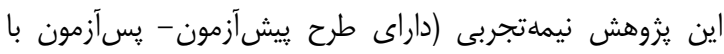

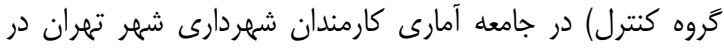

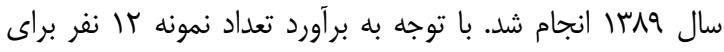

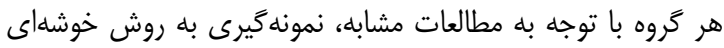

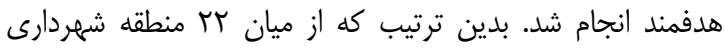

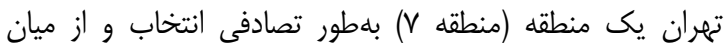

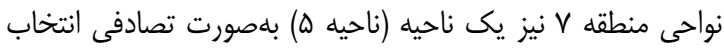

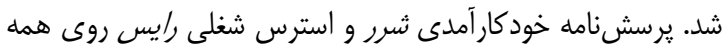

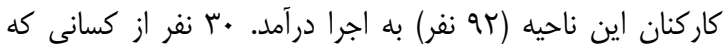

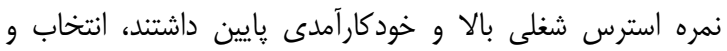

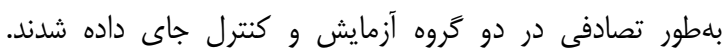

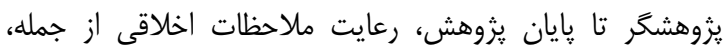

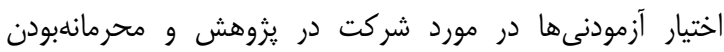
اطلاعات دريافتى را مد نظر قرار داده است.

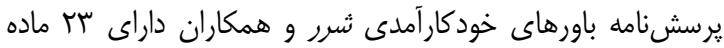

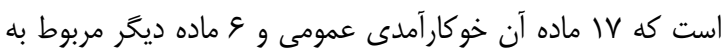

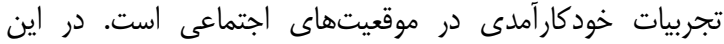

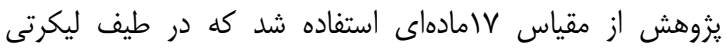

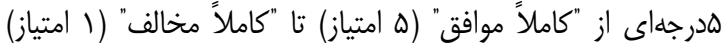

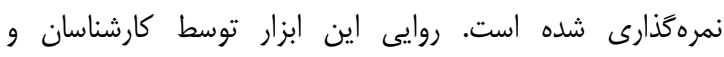

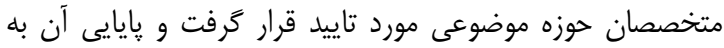

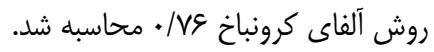

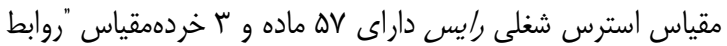

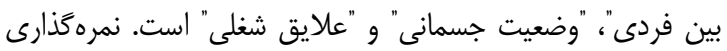

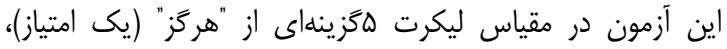

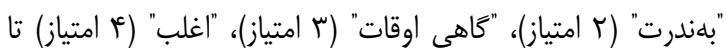

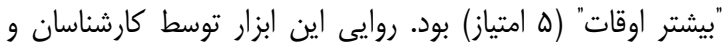

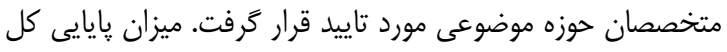

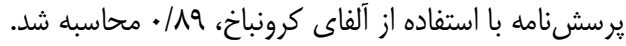

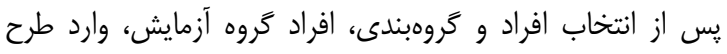

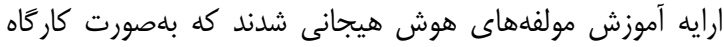

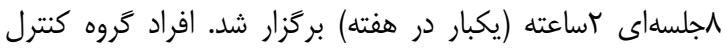

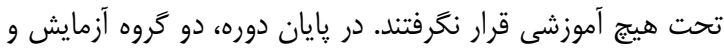

فرد نسبت به توانايىهايش كفته مى شود كه شامل عملكرد موثر در

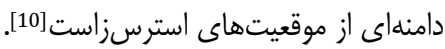

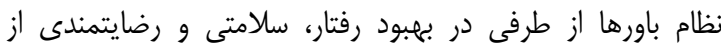

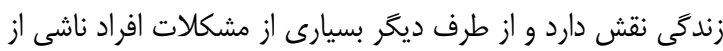

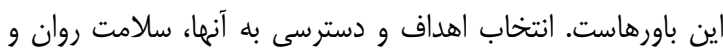

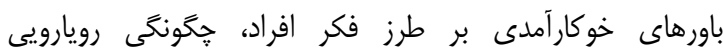
بامشكلات، سلامت هيجانى، تصميمَيرى، مقابله با استرس و و

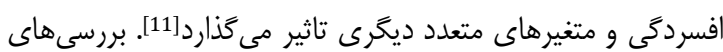
راتهى و راستوجى نشان مى دهد كه هوش هيجانى رابطه مثبتى با

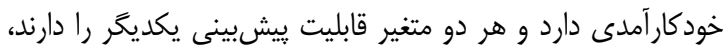
همجنين بررسى هاى ويليام و همكاران و بيورلى و همكاران تاييدى

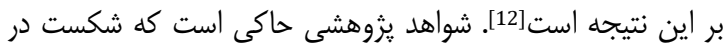

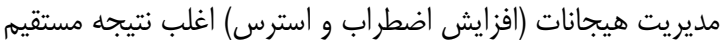

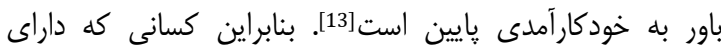
هوش هيجانى بالا و باروهاى خودكار آمدى مثبت هستند به مراتب

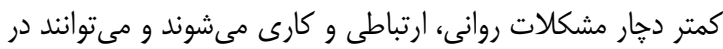

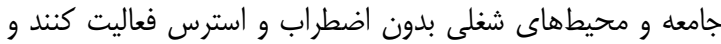
رضايت شغلى قابل قبولى داشته باشند.

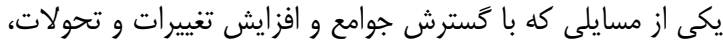

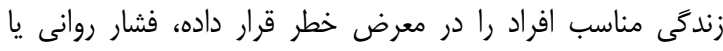

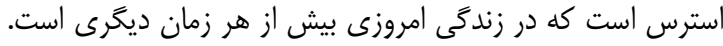

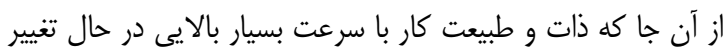
است، هماكنون استرس شغلى بيش از هر زمان ديكرى تهديدى

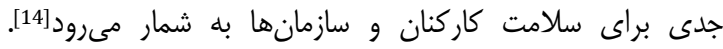
استرس شغلى حالتى ناشى از يك واكنش ناساز كار در برابر رخدادها

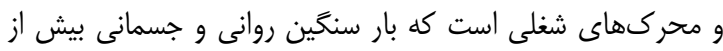

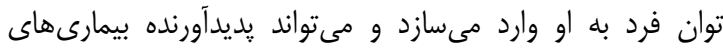

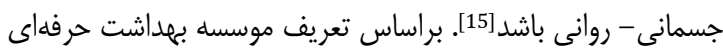

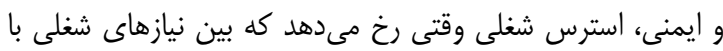

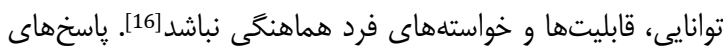

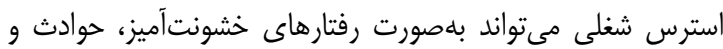
مصدوميتهاى كار، بيمارىهاى جسمانى مختلف و حتى مركى بروز كند. استرس شغلى با رضايت شغلى و عملكرد فرد رابطه مستقيم داشته و يكى از مولفههاى موثر بر سلامت، ايمنى و آسودگى

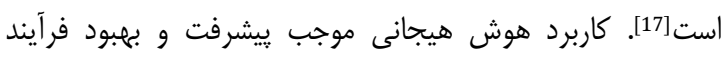

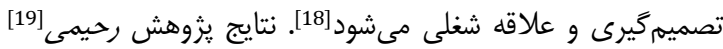

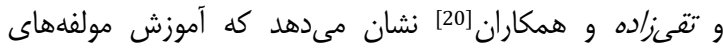
هوش هيجانى در كاهش استرس شغلى موثر است. مجيديان [21]،

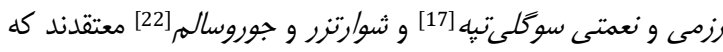

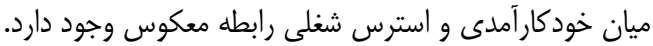

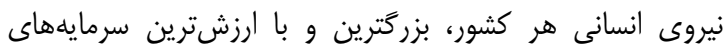
سازمانهاى آن محسوب مى شود. با توجه به تاثير خودكارآمدى و و 


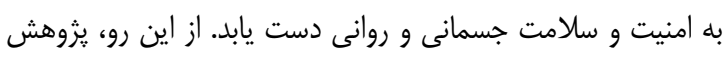

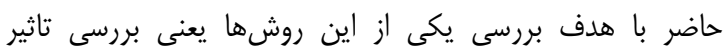

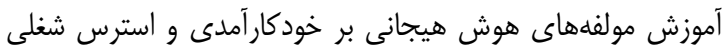

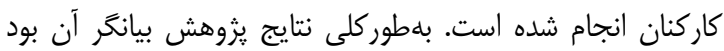

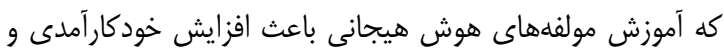
كاهش استرس شغلى مى شود. براساس نتايج مطالعه حاضر، آموزش هوش هئ هيجانى باعث افزايش

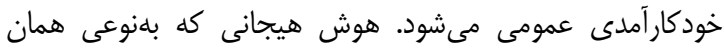

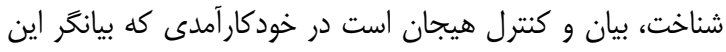

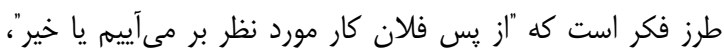

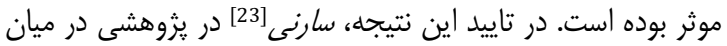

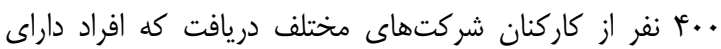

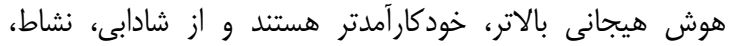

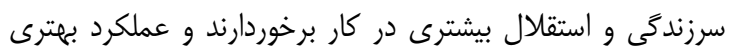

دارند. همجنين اين نتيجه با نتايج يزوهش برون بيرامى [7"] همسوست.

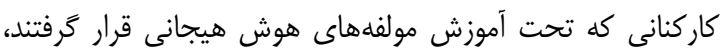
استرس كمترى نسبت به كروه كنترل داشتند، در نتيجه، آموزش كانس

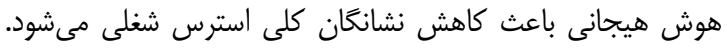

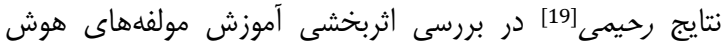

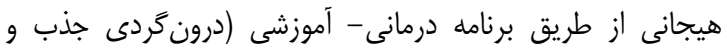

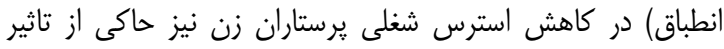

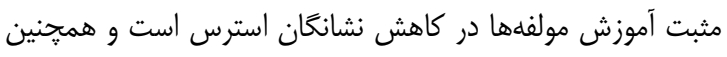
با نتايج تقعز/اده و همكاران [20] همسوست.

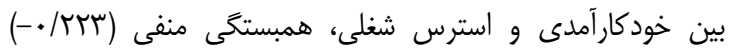

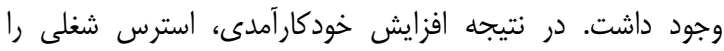

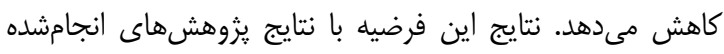
همسو است. يزوهشهاى متعددى به بررسى نقش تعديل كننده

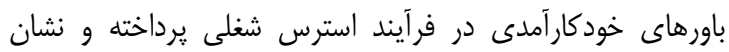

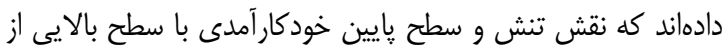

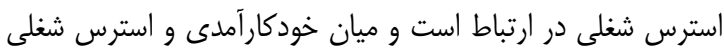
رابطه معكوس معنى دارى وجود دار د[22, 21, 27].

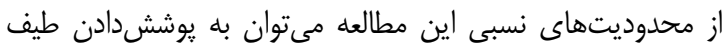

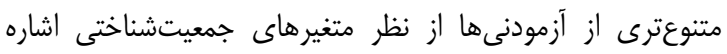

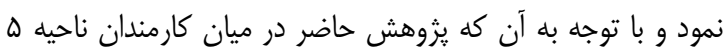

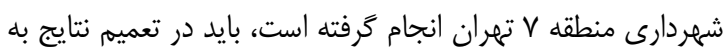

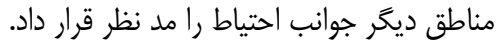

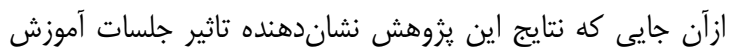

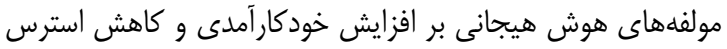

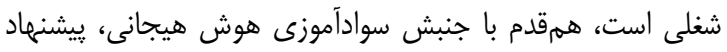

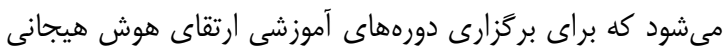

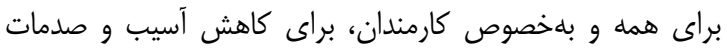
ناشى از استرس شغلى بلهضصوص در مورد مشاغلى كه در دسته
كنترل، براى بررسى سطح خودوكارآمدى و استرس شغران شغلى مجدداً يرسشنامهها را تكميل كردند.

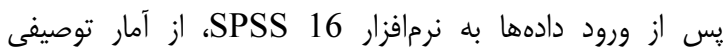

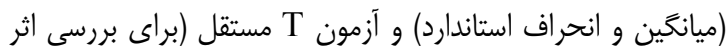

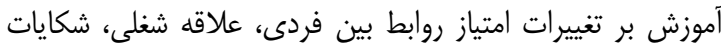
جسمانى ناشى از استرس، خودكارآمدى و كاهش نشير نشانعان كلى رئى

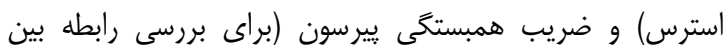

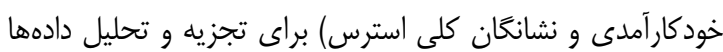

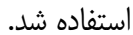

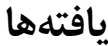

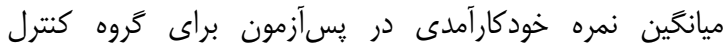

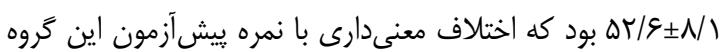

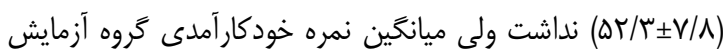
در يسآزمون

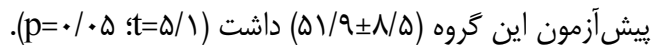

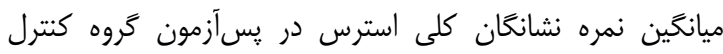
آم /

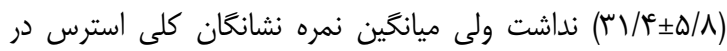
يس آزمون تروه آزمايش

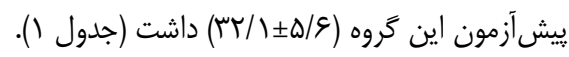

\begin{tabular}{|c|c|c|c|}
\hline سطح معنىدارى & بֶ آزمون & بيش آزمون & شاخص \\
\hline $\begin{array}{l}>.1 .0 \\
.1 .1\end{array}$ & $\begin{array}{l}\mid r / \cdot I \pm r / 4 . \\
q / V \cdot \pm r / q r\end{array}$ & 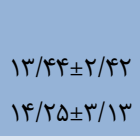 & روابط بين فردى \\
\hline $\begin{array}{l}>.1 .0 \\
. / 14\end{array}$ & $\begin{array}{l}q / F \Delta \pm 1 / q T \\
V / 1 \cdot \pm F / F .\end{array}$ & $\begin{array}{l}V / r \cdot \pm r / T \cdot r \\
V / I \cdot \pm \tau / / f\end{array}$ & وضعيت جسمانى كترل \\
\hline $\begin{array}{l}>.1 .0 \\
.1 .5\end{array}$ & 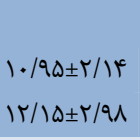 & $\begin{array}{l}11 / 1 \cdot \pm r / 4 \cdot \pm r / A r \\
11 / \theta\end{array}$ & ميزان علاقه شغلى \\
\hline $\begin{array}{l}>.1 .0 \\
.1 .1\end{array}$ & $\begin{array}{l}r r / \Gamma \pm \xi / \Lambda \\
r \Delta / \gamma \pm \xi / \Lambda\end{array}$ & $\begin{array}{l}r / / \Psi \pm \Delta / \Lambda \\
r T / I \pm \Delta / q\end{array}$ & نشانكًان كلى استر كنترل \\
\hline
\end{tabular}

همبستىى منفى معنى دارى بين افزايش خودكارآمدى و كاهش

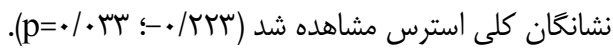

بحث

انسان همواره در صدد كشف مجهولات و حل مشكلات خود بوده

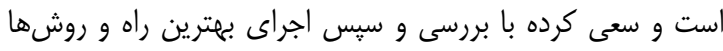

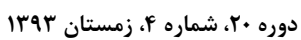

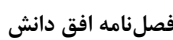


تاثير آموزش مولفههاى هوش هيجانى بر افزايش خودكار آمدى و كاهش استرس شغلى اعن

Academic Press. 2012:71-81.

9- Pajares F. Gender and perceived self-efficacy in selfregulated learning. Theory Pract. 2002;41(2): 116-25.

10- Schwarzer R. (Editor). Self-efficacy: Tought control of action. New York: Taylor \& Francis; 1992.

11- Rabani Bavojdan M, Towhidi A, Rahmati A. The relationship between mental health and general self-efficacy beliefs, coping strategies and locus of control in male drug abusers. Addict Health. 2011;3(3-4):111-8.

12- Amini ZM, Narimani M, Brahmand T, Sobhi Gharamaleki N. The Relationship between Emotional Intelligence With Self- Efficacy and Mental Health in Successes and Non-Successes Students. Knowledge Res Appl Psychol. 2008;35-36:107-22. [Persian]

13- Bandura A. Self-efficacy, the exercise of self control. NewYork: Worth Publishers; 1997.

14- Sauter SL, Murphy LR, Hurrell JJ. Prevention of workrelated psychological disorders: A national strategy proposed by the National Institute for Occupational Safety and Health (NIOSH). Am Psychol. 1990;45(10):1146-58.

15- Keaveney SM, Nelson JE. Coping with organizational role stress: Intrinsic motivational orientation, perceived role benefits, and psychological withdrawal. J Acad Marketing Sci. 1993;21(2):113-24.

16- Bakker AB, Demerouti E, Verbeke W. Using the job demands resources model to predict burnout and performance. Human Resource Manag. 2004;43(1):83-104.

17- Razmi S, Nemati Sogolitapeh F. The moderating role of self- efficacy in relationship between occupational stress with psychological health and job satisfaction of Saderat Bank's staffs of Tabriz. Iran Occup Health J. 2011;8(2):17-0 [Persian]

18- Srivastava K. Emotional intelligence and organizational effectiveness. Ind Psychiatry J. 2013;22(2):97-9.

19- Rahimi Sh. Effectiveness of teaching emotional intelligence components to adapt the internal method for reducing job stress in women working as nurse [Dissertation]. Tehran: Allameh Tabatabai University; 2008. [Persian]

20- Taghizadeh H, Tavakoli M, Miri MR, Akbarzade H. Relationship between emotional intelligence and job stress among managers and employees of teaching hospitals affiliated to Tabriz University of Medical Sciences and Health Care. J Birjand Univ Med Sci. 2010;16 (4) :57-64 [Persian]

21- Majidian F. Study of self-efficacy beliefs and job stress hardiness with high school principals [Dissertation]. Tehran: University of Allameh Tabatabai; 2005. [Persian]

22- Schwarzer R, Jerusalem M. Generalized self-efficacy scale. In: Wright WS, Johnston M. Measures in health psychology: A user's portfolio. Causal and control beliefs Windsor, UK: NFER-Nelson; 1995.

23- Saarni C. Developing Emotional Competence. NewYork: Guilford Press; 1998.

$$
\begin{aligned}
& \text { مشاغل يراسترس با كثرت ارباب رجوع هستند، اقدامات لازم }
\end{aligned}
$$

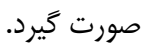

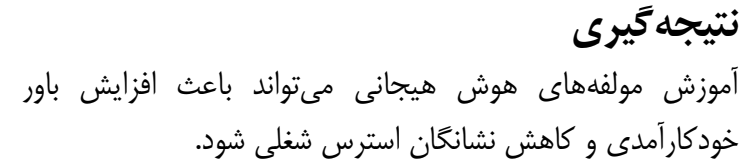

$$
\begin{aligned}
& \text { تشكر و قدردانى: نويسنده بر خود لازم مىداند كه از كارمندان } \\
& \text { ناحيه ه شهردارى منطقه V تهران و تمامى كسانى كه طى ولى اين } \\
& \text { مطالعه همكارى داشتند، تشكر و قدردانى نمايد. } \\
& \text { تاييديه اخلاقى: مجوزهاى لازم از مراجع ذىصلاح اخذ شده } \\
& \text { است. } \\
& \text { تعارض منافع: هيجَّونه تعارضى وجود نداشته است. }
\end{aligned}
$$

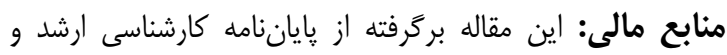

$$
\begin{aligned}
& \text { هزينههاى آن توسط دانشگاه علامه طباطبايى تامين شده است. }
\end{aligned}
$$

\section{منابع}

1- Hosseini Sadeh SM, Fathi-Ashtiani A. The role of emotional intelligence and its components in marital satisfaction and compared with demographic variables. J Psychol Religion. 2009;2(2):105-30. [Persian]

2- Esmaeili M, Ahadi H, Delavar A, Shafie Abadi A. Effect of emotional intelligence on psychological health. Iran J Psychiat Clin Psychol. 2007;13(2):158-65. [Persian]

3- Mayer JD, Salovey P. Emotional intelligence as a standard intelligence. Emotion. 2001;1(3):232-42.

4- Riggio RE, Reichard RJ. The emotional and social intelligences of effective leadership; an emotional and social skill approach. J Manag Psychol. 2008;23(2):168-85.

5- Baron RM. The Bar-On model of emotional-social intelligence (ESI). Psicothema. 2006;18(1):13-25. [Spanish] 6- Hoveyzavi Z, Enayati MS. Investigate the effect of emotional intelligence on methods of coping with stress among secondary school students in Ahvaz. J New Findings Psychol.2010;5(14):95-109. [Persian]

7- Bayrami M. The Effectiveness of assertiveness training on self-efficacy emotional intelligence and mental health of students. J Psychol. 2008;3(11):25-42. [Persian]

8- Bandura A. Self-efficacy. In: Ramchaudran VS. (Editor). Encyclopedia of human behavior. $2^{\text {nd }}$ ed. New York: 